\title{
Parents' Gender-Based Attitudes Toward Marital Roles and Child Rearing: Development and Validation of New Measures ${ }^{1}$
}

\author{
Lois W. Hoffman ${ }^{2}$ and Deborah D. Kloska \\ University of Michigan
}

Factor analysis of 18 Likert-type items dealing with gender stereotypes about family roles was conducted and yielded two measures: one focused on marital roles and one focussed on child rearing. Respondents were parents of children in the third and fourth grades of a large industrialized city in the Midwest. The sample included 364 families equally divided between middle and lower class with 23\% African American and 77\% European American. For both scales, more stereotyped scores were obtained by parents who were lower in social status, less educated, full-time homemakers, African Americans, and fathers. Parents' scores related to a separate measure of children's stereotypes and the marital-role attitudes related to actual roles reported by family members. Daughters whose parents obtained less stereotyped scores had a more internal locus of control, showed a trend toward more independent coping skills, and-in the middle class-obtained higher scores on achievement tests.

Research over the past two decades has not only demonstrated gender differences in children's behavior, attitudes, and personality (Huston, 1983; 1985), but has also shown that the relationships between family experiences, such as parental divorce and the mother's employment status, are different for sons than for daughters (Hetherington \& Camara, 1984; Hoffman, 1989). Many of these gender differences have been linked to the different socialization that boys and girls experience in the family (Block, 1973; 1983; Fagot, 1982; Hoffman, 1977; Lytton \& Romney, 1991). It has been sug-

\footnotetext{
${ }^{1}$ This research was supported by Grant No. 91-1437-91 from the William T. Grant Foundation.

${ }^{2}$ To whom correspondence should be addressed at Department of Psychology, University of Michigan, Ann Arbor, MI 48109-1027.
} 
gested that boys and girls are treated differently by parents, that the roles each parent enacts are gender specific and thus lead to differences in the self-concepts and behaviors that boys and girls take on, and that parents communicate overtly and covertly their own gender stereotyped attitudes which affect their children's self-concepts, motivations, and behavior.

Some developmental psychologists focus on a cognitive process in which the child learns his or her own gender and its permanence and adopts the "gender appropriate" self-concepts and behaviors (Kohlberg, 1966); others focus on the self-attributions the child makes in response to the way he/she is treated and described by the parents (Eccles, 1985); others focus on the rewards and punishments meted out that shape the child along gender-typed lines (Fagot, 1978); and still others focus on the direct teaching and verbalized attitudes of parents about what males and females are like or should be like (Hoffman, Paris \& Hall, 1994). For all of these theories, key elements in the process are the behaviors and attitudes of the parents. Some of the behaviors and attitudes have to do with how the parents treat the child; some have to do with the roles enacted by each parent (Baruch \& Barnett, 1981); some have to do with what they say (Brooks-Gunn, 1985).

Researchers seeking to identify the roots of gender differences in the family need to have measures that can tap parents' behavior and attitudes. Attitude measures alone are often not sufficient because parents who express an equalitarian view toward gender may nevertheless treat sons and daughters differently because of their own internalized and unconscious views or because of the different stimuli children of each gender present which evoke different reactions in the parent (Fagot, 1974; Hoffman, 1977). Similarly, behavioral measures alone may not be sufficient, particularly if one is interested in unraveling the full socialization process, or in drawing conclusions about effective intervention policies (Brooks-Gunn, 1985). Are the behaviors attitude-driven? Does the causal process involve an effect on parents' attitudes which affects their behavior? Are effects different if there is incongruence between attitudes and behavior?

In some research, however, either alone may be adequate. In socialization research where one is seeking to identify the link between a demographic family variable, like the mother's employment status, and child outcomes that show gender differences, either gender-specific attitudes or behavior might be examined. In such studies, the choice is usually to study attitudes. While behavior can sometimes be tapped by verbal techniques, often direct observation is needed. The latter is a more expensive and timeconsuming process. It is difficult to use in large-scale surveys or in research where gender-stereotyping is but one of many variables. It is therefore not surprising that recent years have seen a proliferation of measures of gender attitudes. Measures have been developed to tap concepts of masculinity 
and femininity (Bem, 1974; Spence, Helmreich, \& Stapp, 1974), attitudes toward women (Spence, Helmreich, \& Stapp, 1973; Belk \& Snell, 1986), attitudes toward women's employment (Greenberger, 1988), gender-role stereotypes about adults (Deaux \& Lewis, 1984; Rosenkrantz, Vogel, Bee, Broverman \& Broverman, 1968; Martin, 1987), and parents' gender-based stereotypes about children's behavioral predispositions (Brooks-Gunn, 1985; Fagot, 1974). Indeed, not only have enough measures been developed to fill a book, but they do (Beere, 1990).

Surprisingly, however, there are few measures of gender stereotyped attitudes about family roles that have been developed in recent years. Furthermore, most of the existing measures consider only the husband-wife roles and were developed by sociologists for use in studying fertility behavior, marital satisfaction, or women's labor force participation, not for studying children's socialization. The purpose of the present paper is to present two new measures, one to measure parents' gender-role attitudes toward marital roles and the other to measure their gender-based attitudes toward child rearing. These two dimensions seem major in affecting the child's gender-role socialization. The parents' roles viz-à-viz each other affect the models that the child observes, while differences in child-rearing attitudes toward sons and daughters affect the child's direct experience. Parents' attitudes on both these dimensions should directly, or through their corresponding behavior, affect children's constructions of the nature of the world, their self-concepts, and their behavior.

Both measures introduced here are short and can be self-administered. In this report, they will be described and related to various demographic variables, other aspects of the family situation, and relevant child attitudes and behavior as an indication of their construct validity. Both measures are intended primarily for socialization research.

In the first section below, previous measures of gender-based attitudes toward marital roles and gender-based attitudes toward child rearing are reviewed. Following that, the sample and data base used in the development of the new measures and the ensuing validation analysis are described. We then detail the scale construction and the factor analysis from which the two scales emerged. The final section of the paper deals with the validation of the scales-first by examining their relationship to various demographic variables, then by seeing how they related to the division of labor in the family as reported by mothers, fathers, and children, and finally by exploring their predictive value. Hypotheses are tested about the relationships between each scale and children's gender stereotypes, locus of control scores, teacher ratings of independence, and achievement test scores. 


\section{REVIEW OF PREVIOUS MEASURES}

\section{Previous Measures of Gender-Role Traditionalism in Husband-Wife Relations}

Several measures of gender stereotyping in attitudes toward husbandwife roles were developed in the 1950's (Dunn, 1960; Jacobson, 1950; Hoffman, 1960), but almost forty years of social change have made these outmoded. The more recent scales developed by Scanzoni (1975) have had a considerable influence in sociology, and are still widely used. They, too, however, seem dated in light of today's views. For example, two of the items are "If she has the same job as a man who has to support his family, she should not expect the same pay" and "A wife should give up her job whenever it inconveniences her husband and children." Furthermore, given the fact that $75 \%$ of all married mothers of school-aged children in this country are currently employed, as are $56.7 \%$ of those with infants one or under (U.S. Bureau of the Census, 1993), the current usefulness of the scales is limited by their heavy reliance on approval or disapproval of wives' participation in the labor force. The Scanzoni scales, like the earlier, do include items tapping attitudes toward the division of labor and the division of power between the spouses and both of these dimensions seem to be important ones to include from the standpoint of the child's socialization experiences.

\section{Previous Measures of Parents' Gender-Based Child-Rearing Attitudes}

Our original search of the literature yielded no measure of parents' gender-based attitudes toward child rearing. However, since completing the research reported here, two have been found (Burge, 1981; Katz \& Walsh, 1991). Beere (1990) lists only one measure of gender-based child-rearing attitudes in her comprehensive handbook on gender-role measures, the scale developed by Burge (1981). In fact Beere states, "A major reason for including this scale . . . is that item content is quite different from what is typically found on gender-role attitude scales" (p. 496). This seems surprising in view of the relevance of gender stereotyping in child-rearing attitudes for children's socialization. The scale, developed by Burge (1981), includes 28 statements dealing with prescribed behaviors for boys and girls, career goals, acceptable expressions of emotions and suitable toys. The scale has been used in only the original study which did not include validation but did show a correlation with the Osmond-Martin Sex-role Attitude Scale (1975). 
The second measure, developed by Katz and Walsh (1991), focuses on parents' reactions to counter-stereotyped behavior. Parents are asked, for example, how they would feel if their daughter wanted to play football, if they would discourage their son from acting like a girl, and how they would feel if their son, as an adult, were more active than his wife in caring for their baby.

The measure developed here is more similar to the Burge measure than the Katz and Walsh in that it is more focused on attitudes toward independence and achievement, two qualities that have been examined as important for sex differences in adult motivation and behavior (Eccles, 1985; Hoffman, 1972). In addition, the new scale includes one item similar to an item in the Burge scale, "I would buy my son a doll."

In the first section below, we describe the sample used in these analyses, then the gender attitude items originally administered, a factor analysis of the items, and the two scales that emerged from this analysis. In the second section, we deal with tests of the construct validity of the two scales. Here we describe measures used in examining relationships between each of the two scales, Gender-based Attitudes toward Marital Roles and Gender-based Attitudes toward Child Rearing, and other family and child variables, and then examine the relationships between each parent attitude measure and the demographic variables previously noted to relate to gender-role traditionalism as well as measures of the division of labor in the family, and the children's sex-role stereotypes, locus of control; teacherrated independence, and achievement test scores.

\section{TWO MEASURES OF PARENTS' GENDER-BASED ATTITUDES}

\section{Sample}

The sample used in these analyses includes 364 families from a large midwestern industrial city who were part of a larger study on the effects of maternal employment on family interactions and child outcomes. The data were collected in Spring of 1992. All of the families included a child in the third or fourth grade of the public schools. The sample represents a broad socioeconomic range (8-66 on the Hollingshead Four-Factor Index representing an approximately equal division between lower- and middleclass); $23 \%$ are African American and the rest are European American. Subjects were recruited for the study by requesting parental permission through the schools. Out of the total population of third and fourth grade students in the participating schools, parental permission was received for $82 \%$ of the children, and $73 \%$ of the mothers also agreed to be interviewed. 
Only the latter group are included in this analysis. The present analysis includes 253 married mothers, 111 single mothers, and 213 fathers. Mothers were interviewed in their homes. Married mothers were given questionnaires for their husbands to complete and mail back to the researchers. Eighty-five percent of the fathers returned their completed questionnaires. In addition to the data collected from parents, all children in this analysis were individually interviewed in their schools, teachers rated the children's behavior, and achievement test scores were provided by the schools.

\section{Factor Analysis}

The actual measure from which the gender-role attitudes were culled consisted of 22 statements to which the respondent was asked to indicate if he or she strongly agreed, agreed, disagreed, or strongly disagreed. The 22 statements are listed in Table I. ${ }^{3}$ The following items were not included in the factor analysis: $3,4,5,11$. They are measures of Locus of Control which were interspersed to break the set. Three items, 8,15 , and 22, do not deal with family roles and were not expected to be part of the final scales, but they were included in the factor analyses to see if they did fall into one of two possible husband/wife role factors. They did not and are not included in the final scale.

In constructing the items for the scale, we were trying to measure three dimensions of family role attitudes: the division of labor between the man and wife, the division of power between them, and gender-based attitudes toward child rearing. ${ }^{4}$ As a first step, oblimin rotations were conducted for the sample of married mothers using split-half factor analysis. Three and four factor solutions were obtained using a principal axis factoring technique in SPSSX. From this original factor analysis, items 1 and 16 were dropped. These two items had lower loadings than the others or loaded by themselves; they did not contribute to the reliability of the scale. From this first analysis, a revised set of three factors was determined. The childrearing factor remained the same. The three items, 8,15 and 22 all loaded with the power division factor.

Principal Axis Factoring was next done on the entire sample of married mothers to obtain loadings for the three scales setting FACTORS $=3$ in

\footnotetext{
${ }^{3}$ The 22 items were placed in both the mother's interview and the father's questionnaire just after a set of questions about which parent performed each of 48 specific household tasks and parenting roles.

${ }^{4}$ To the best of our knowledge all items used in the GATMR and the GATCR were created by the first author. However, items 3, 7, and 14 were included in scales previously constructed by the first author (Hoffman, 1960). Item 20 was an original item, but as noted in the text, is similar to an item included in the Burge scale (1981).
} 
Table I

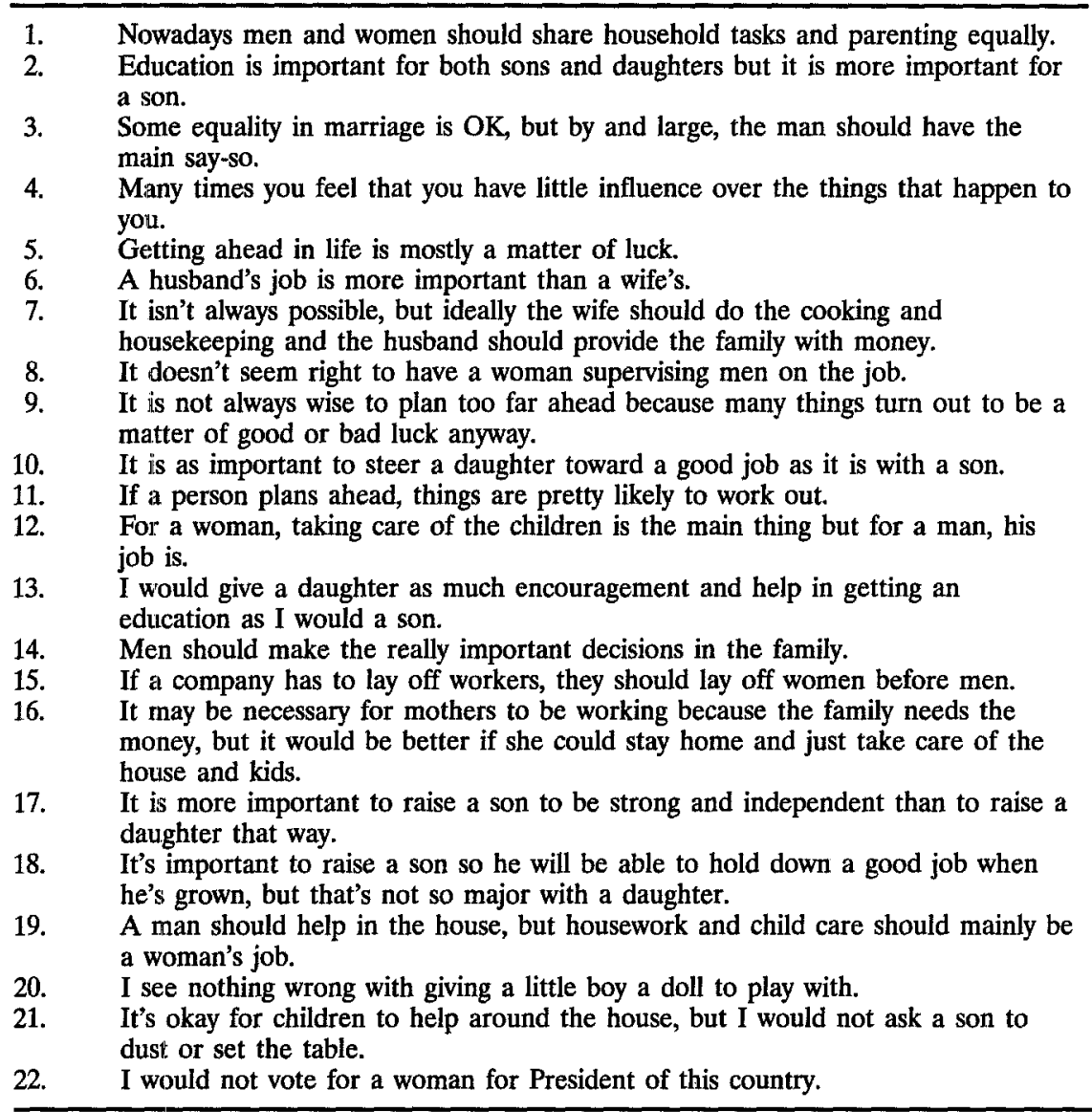

the SPSSX subroutine. In doing this, it was discovered that the husband/wife power items did not really fit together and tended to load with the division of labor factor. Based on this and the fact that the final statistics also revealed only two factors with eigenvalues greater than 1 , we dropped the three nonfamily items and decided to use a two-factor solution: Child Rearing with seven items and $\alpha=.85$, and Marital Roles with six items and $\alpha=.83$. Oblimin solution loadings ranged from .41 to .80 on Child Rearing, and .58 to .75 on Marital Roles. The scales with item loadings indicated are listed in Table II. The correlation between the two scales for married mothers was .70 .

Fathers' responses were then randomly split for principal axis factoring. The Marital Role items factored very similarly to the mothers' solution. 
Table II. Factor Analysis: Gender-Based Attitudes

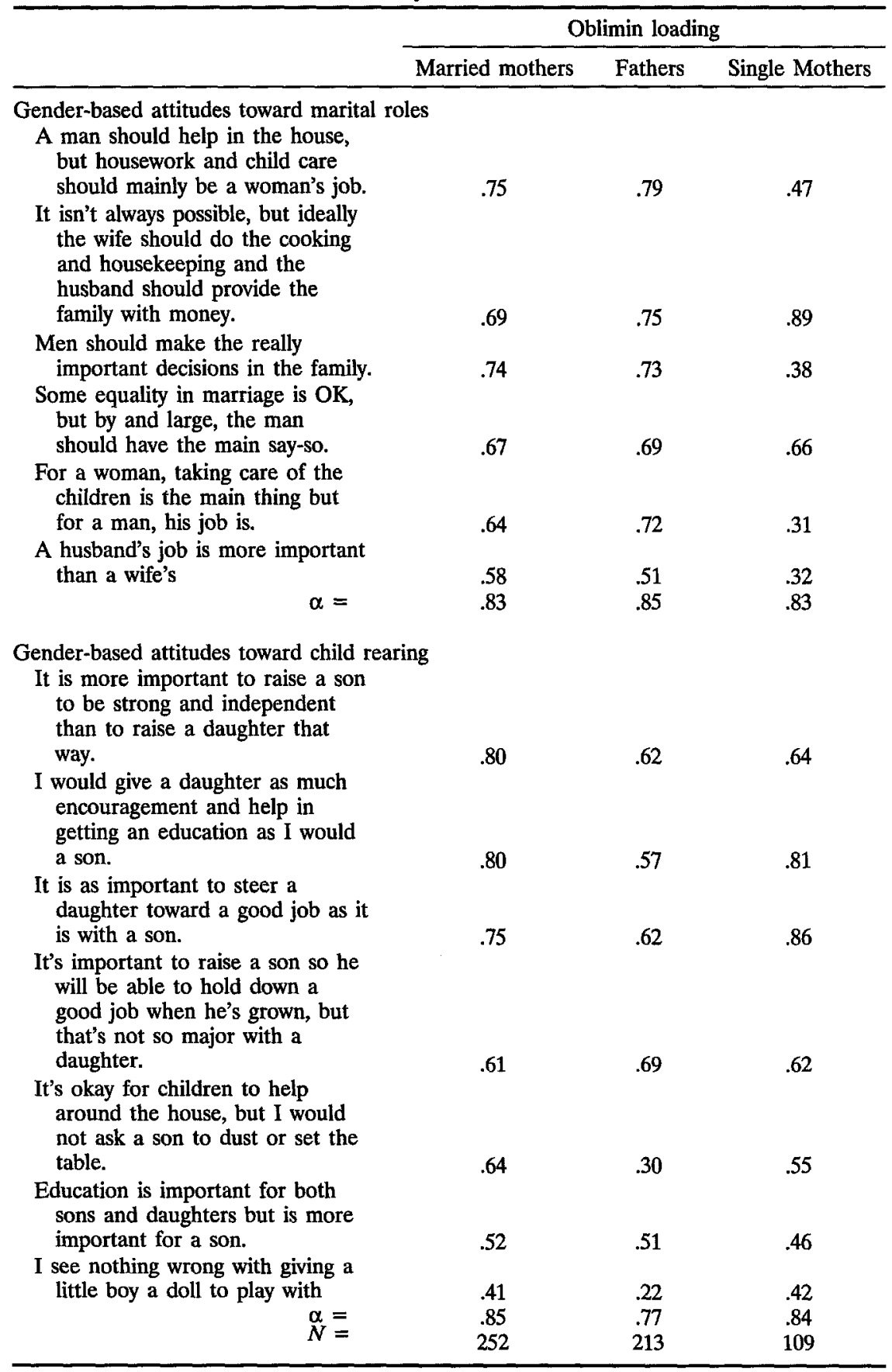


Again, items 1 and 16 either loaded by themselves or had poor loadings on the factors where they did load. The Child Rearing items were split over two factors. The full father sample was then factor analyzed so loadings could be determined for the revised married mother two-factor solution. The Marital Role factor came out for the full sample with $\alpha=.85$, and item loadings ranging from .51 to .79 on the oblimin solution. For Child Rearing, $\alpha=.77$, with item loadings ranging from .22 to .69 on the oblimin solution. (See Table II). The correlation between the two scales for fathers was .60 .

Principal Axis Factoring was next done for the single mothers using all eighteen items. Because of the smaller $n$, the entire sample of single mothers was used. The Child Rearing items factored very similarly to the married mothers' solution, and the Marital Role items split on two other factors. The analysis was then run requiring just two factors be determined. This resulted in the Marital Role scale with $\alpha=.84$ and item loadings ranging from .31 to .89 on the oblimin. The Child Rearing scale yielded $\alpha=.83$, with item loadings ranging from .42 to .86 . The correlation between the factors for the single mothers was .54 .

The final items for each of the two scales are listed in Table II. Scoring consisted of assigning weights of 1 for "strongly agree," 2 for "agree," 3 for "disagree" and 4 for "strongly disagree," with the first two items and the last in the Gender-based Attitudes Toward Child Rearing scale reverse scored. The weights are summed across each measure. ${ }^{5}$ The Gender-based Attitudes Toward Marital Roles scale (GATMR) has a possible range of 6 to 24; the Gender-based Attitudes Toward Child Rearing scale (GATCR) has a possible range of 7 to 28 . For both scales, a high score indicates less gender stereotyping.

Although each scale taps a different dimension of sex-role traditionalism, they are highly correlated, as would be expected $(r=.63 ; p<.001)$. As also expected, the correlations between spouses' scores is significant (for Gender-based Attitudes Toward Marital Roles, $r=.37 ; p<.01$, and for Gender-based Attitudes Toward Child Rearing, $r=.29 ; p<.01$ ).

\section{CONSTRUCT VALIDATION}

To establish construct validity of the two measures, two approaches were taken. The first was to see if each measure related to various demographic variables as would be expected from previous research findings. It

\footnotetext{
${ }^{5}$ Three respondents failed to answer all of the items used in the factor analysis and were not included. If an unanswered item was part of the final scale, that item was assigned a value equal to the average of the items in the scale that the respondent did answer.
} 
was predicted that each scale would relate to socioeconomic status, education, the gender of the respondent, the mother's employment status, mother's marital status, and ethnicity. We expected less gender stereotyped scores for respondents with higher socioeconomic status, higher educational achievement, for women in comparison to men, employed mothers, and single mothers in comparison to married when social class was controlled. For ethnicity, previous research provides conflicting data. Effects of ethnicity might be different for the two scales, and gender and social class might moderate the relationships.

Previous research has found gender-role traditionalism negatively related to education with considerable consistency (Thornton, Alwin \& Camburn, 1983; Schaninger, \& Buss, 1986; Scanzoni, 1975). A negative relationship is also often found for social class, but here the results vary somewhat depending on how social class is operationalized. Schaninger and Buss (1986), for example, found that the husband's high occupational status predicted nontraditional family views, but his high income predicted traditional ones. Since the measure of social class used in this analysis is based on status rather than income, it was expected that higher socioeconomic status would be associated with less traditionalism.

Gender and the mother's employment status have also shown a relationship to sex-role traditionalism across measures. Studies examining the effects of gender on a wide variety of gender attitude scales find women less traditional (Beere, King, Beere, \& King, 1984; Entwisle \& Greenberger, 1972; Vogel, Broverman, Broverman, Clarkson, \& Rosenkrantz, 1970; Greenberger et al., 1988; Burge, 1991).

The mother's employment status has more often been examined in relationship to her children's traditionalism than to her own. These studies have demonstrated that children of employed mothers, from preschool age through adulthood, hold less gender stereotyped views, with the finding somewhat more consistent for daughters than for sons (Hoffman, 1989; Huston, 1983; Zaslow, 1987). However, research has also shown that more liberal views toward gender roles are held by the employed women themselves as well as their husbands (Scanzoni, 1975; Greenberger et al., 1988; Hoffman, 1960; Smith, 1985).

Few studies have examined the effects of the woman's marital status on gender attitudes, but the limited data available suggest that single mothers hold a less traditional view of marital roles (Barber, 1990; Barber \& Eccles, 1992). In addition, in a study of lower income women going through a divorce, Brown and Manela (1978) found a shift toward less gender stereotyped attitudes accompanied this experience.

The relationship between ethnicity and gender-role traditionalism is not clear. Several writers have hypothesized that African Americans hold 
more liberal views about gender roles in the family, an expectation based largely on their long history of female employment. The data, however, paint a more complicated picture. Scanzoni (1975) found that African American men hold significantly more traditional views about wives' family roles than do European American men. For women, he found the same pattern, but it did not achieve satisfaction significance. However, on a scale dealing with the importance of a woman's occupation, he found both African American men and women less traditional. Herzog, Bachman, and Johnson (1983) found a similar pattern in a study of high school seniors, and other recent publication have reported similar results (Binion, 1990; McLoyd, 1993). In the present analysis, ethnic differences on the two scales will be examined, but no prediction about results is made.

The second approach was to examine the relationship between the scales and other measures to which these attitudes might be expected to predict. These measures include: the existing division of roles between the husband and wife as reported by the mother, father, and child; the children's gender-role stereotypes; two measures of the children's independence, teacher ratings of independent coping skills and children's responses on a Locus of Control scale; and scores on academic achievement tests.

It was expected that more nonstereotyped scores on the Gender-based Attitudes Toward Marital Roles scale (GATMR) would relate to relatively higher participation by fathers in traditionally feminine household tasks. In addition, nonstereotyped scores on both measures, Gender-based Attitudes toward Marital Roles (GATMR) and Gender-based Attitudes toward Child Rearing (GATCR), were expected to relate to scores indicating less gender-stereotyping by both boys and girls.

Finally, for additional validation, hypotheses were tested about child outcomes that might be associated with the two measures. A number of theoretical papers have suggested that parents' gender-stereotyped behavior and attitudes function to diminish daughters' sense of personal control, independence, and achievement behavior (Eccles \&: Hoffman, 1984; Hoffman, 1972). This effect is thought to occur through girls' observations of the interactions between their parents, through the way they are treated, and through the views they hear their parents express. It has rarely been demonstrated empirically, but a notable exception is a study by BrooksGunn (1985) which found that mothers who held more gender-based stereotypes about toddlers engaged in less active toy play with their daughters, and their daughters scored lower on cognitive indices tapped by the Bayley Scale of Infant Intelligence and the Stanford Binet at 24 and 36 months of age. 
It was our expectation that Gender-Based Attitudes toward Child Rearing would be related to daughters' locus of control, independent coping, and achievement test scores, with less stereotyped child-rearing attitudes predicting more internal locus of control, more independent coping, and higher achievement scores. No relationship was expected for boys. This prediction is based on the idea that gender-stereotyped child-rearing attitudes tend to diminish daughters' independence and achievement but are not dysfunctional nor advantageous for sons (Hoffman, 1972). Thus nonstereotyped attitudes would be more beneficial to daughters. Attitudes toward marital roles seem more removed from these outcomes, but since equalitarian marital roles are more consonant with a view of women as independent, or more empowered, it seemed possible that the GATMR would also relate to the two measures of independence for daughters, but no prediction was made about the achievement scores. The specific hypotheses were that less stereotyped scores on both the Gender Attitudes toward Marital Roles and the Gender Attitudes toward Child Rearing would relate to more internal Locus of Control scores and higher teacher ratings of Independent Social Skills for daughters but not sons, and that less stereotyped scores on the Gender Attitudes toward Child Rearing would also relate to higher scores on the achievement tests for daughters but not sons.

\section{Measures}

Demographic Data. All demographic data were reported by the mother in a personal interview. The measure of socioeconomic status used is the Hollingshead Four Factor Index of Social Status (1970). This index is based on occupation, marital status, education, and gender. It was chosen for the study because it takes account of the mother's employment and marital status and is, therefore, better suited to a population which includes a higher percentage of single and employed mothers. Measures which rely on income, for example, can be misleading as an index of status because a family with two employed parents who are factory workers can score higher than a single-wage family where the father has a professional occupation, though that does not represent their life styles or community status. Similarly, this measure uses the education and occupation of a supporting spouse in the case of a single mother who is not employed. The measure of socioeconomic status used here, however, is not independent of the measure of parents' education.

Division of Tasks Between Husband and Wife. All married parents were asked to complete a 48 -item questionnaire which listed various household 
tasks and activities and asked the parent to indicate "Who does it more?" Possible responses were: mother-not father, mother mostly but father sometimes, both pretty equally, father mostly but mother sometimes, father-not mother, and neither does it. Weights of 0 to 4 were assigned to each response so that "mother not father" was given a weight of 4 and decreasing values given with "father not mother" given a weight of 0 . "Neither," like "both pretty equally," was given a weight of 2 . To obtain a score for the parents' relative participation in tasks considered traditionally feminine, weights were summed across the ten items so classified (e.g., cleans and dusts, cooks the evening meal, does the dishes).

A very similar measure was personally administered to the children. The items asked about were the same, but the format was different. They were not asked who did each task more, but rather to indicate who did it most of the time and then who did it sometimes but not as much. They were allowed to say that more than one person did it most of the time. The children also were not restricted to saying the parents did the activity, but could name others. Their responses were coded to indicate which parent did it more or whether they did it equally or not at all and weights were similarly assigned and summed to yield comparable scores. This measure has been used in previous research (Hoffman, 1960) and is based on a technique developed by Herbst (1952).

Children's Gender Stereotypes. A measure was administered in the classroom to the children which was based on a measure developed by MillerRosenwasser (Miller, 1975) for kindergarten children and later adapted for older children by Signorella and Liben (1985). Our version consisted of a list of 31 activities which were presented to the child. The child was asked to indicate if this was something only men could do, something only women could do, or something both could do. Some of the items were stereotypically male (e.g., build a house); some were stereotypically female (e.g., bake cupcakes); and some were neutral (e.g., go to the beach). Only the 25 gender-typed activities were scored. Each answer which indicated that only men could do the male activities or only women could do the female activities was scored 0 ; each answer that indicated both or the counter-stereotyped choice received one point. Scores were summed to yield three scores: a score for the activities stereotyped as male, a score for the activities stereotyped as female, and a total score which consisted of the sum of the two. Inter-item reliability was $\alpha=.83, .84, .90$, respectively.

Teacher Ratings of Independence. All children in the classrooms involved were rated by their teachers on the Teacher-Child Rating Scale (Hightower, Work, Cowen, Lotyczewski, Spinell, Guare, \& Rohrbeck, 1986). One dimension of this scale, which is based on summing scores over several discrete behaviors, taps an independent coping style called "Asser- 
tive Social Skills." An example of the Behaviors rated is "defends own views under pressure" (inter-item reliability, $\alpha=.90$ ). This is the measure used in the present analysis.

Locus of Control. The Nowicki and Strickland (1973) measure of Locus of Control was administered to the children. This scale taps the extent to which the child feels in control of his or her own life (internal locus of control) as opposed to feeling that control is in the hands of others or depends on luck (external locus of control). This 18 -item measure yields a composite score with high scores indicating external locus of control and low scores indicating internal $(\alpha=.60)$.

Achievement Tests. Standard achievement tests, the Metropolitan Achievement Test and the Otis-Lennon Ability Test, tapping competence in reading, language, and math, were administered to the children by the schools. Standardized scores were made available for this research and used in this analysis.

\section{Results of the Demographic Analyses}

T-tests for the significance of differences between means were performed for all of the demographic variables on both the GATMR and the GATCR. The results are reported in Table III.

Social Class and Education. For both social class and education, the predicted relationships were found. Higher social class and higher educational achievement each predicted to more nontraditional scores on both the GATMR and the GATCR. T-tests were also conducted for each of the following subgroups: men only, married mothers, single mothers, and African Americans. In each case, the t-test results showed the same pattern and achieved statistical significance. In addition, a series of ANOVAS were conducted for each scale: two-way ANOVAS with class and parent gender and class and marital status, and three-ways with class, gender, and ethnicity. In each case, the main effects of social class were significant and no interactions were found.

Gender. As predicted, the men in the sample obtained more traditional scores on both measures than did the married women. These results were statistically significant for the whole sample as shown in Table III, and also within each social class.

Mother's Employment Status. Consistent with previous findings, the fulltime employed mothers indicated a less gender-based attitude toward both gender roles and child rearing. Furthermore, this same relationship held with the same level of statistical significance when we compared all employed women, full-time and part-time, to the full-time homemakers. 
Table III. Mean Difference on the GATMR and GATCR for Demographic Variables ${ }^{a}$

\begin{tabular}{|c|c|c|c|c|c|}
\hline Demographic variable & GATMR & GATCR & $S D$ & $T$ value & $N$ \\
\hline \multicolumn{6}{|c|}{ Social class (Hollingshead 4-factor index) } \\
\hline Lower class $(8-37)$ & 17.45 & 22.63 & $3.44,2.83$ & \multirow[t]{2}{*}{$5.30,^{e} 6.60^{e}$} & 314 \\
\hline Middle class (38-66) & 18.92 & 24.18 & $3.14,2.77$ & & 262 \\
\hline \multicolumn{6}{|l|}{ Education } \\
\hline High-school or less & 17.40 & 22.56 & $3.51,2.94$ & \multirow[t]{2}{*}{$4.16,^{e} 5.30^{e}$} & 225 \\
\hline Post high school & 18.59 & 23.84 & $3.22,2.78$ & & 351 \\
\hline \multicolumn{6}{|l|}{ Gender } \\
\hline Married women & 18.36 & 23.66 & $3.10,2.78$ & \multirow[t]{2}{*}{$2.56^{b, d} 2.33^{d}$} & 253 \\
\hline Married men & 17.54 & 23.03 & $3.69,3.00$ & & 213 \\
\hline \multicolumn{6}{|l|}{ Mother's employment } \\
\hline $\begin{array}{l}\text { Full time employed } \\
\text { Homemaker and part }\end{array}$ & 19.62 & 24.24 & $3.14,2.68$ & \multirow[t]{2}{*}{$5.77,^{e} 3.94^{e}$} & 139 \\
\hline time & 17.74 & 23.05 & $2.93,2.87$ & & 221 \\
\hline \multicolumn{6}{|l|}{ Married status } \\
\hline Married mothers & 18.36 & 23.66 & $3.10,2.78$ & \multirow[t]{2}{*}{$.77,1.74^{c}$} & 253 \\
\hline Single mothers & 18.64 & 23.10 & $3.25,2.96$ & & 111 \\
\hline \multicolumn{6}{|l|}{ Ethnicity } \\
\hline African Americans & 16.88 & 22.04 & $3.45,2.82$ & \multirow[t]{2}{*}{$4.48,^{e} 5.54^{e}$} & 117 \\
\hline Non African Americans & 18.43 & 23.67 & $3.30,2.84$ & & 459 \\
\hline
\end{tabular}

${ }^{a}$ High score on both scales indicates a less gender-stereotyped attitude.

${ }^{b}$ Based on separate variance estimate.

$c p<.10$, two tailed.

$a_{p}<.05$, two tailed.

$e_{p}<.001$, two tailed.

Mother's Marital Status. For the measure of gender-based attitudes toward marital roles (GATMR) there was no difference between single and married mothers; for the GATCR, the direction of the relationship ( $p<$ .10) was not in the expected direction when the data were examined without control for social class (Table III). However, single mothers are more predominant in the lower class and, as already indicated, lower class status is associated with more traditional scores. In addition, ethnicity is also related to marital status and the two attitude scales (Table III). A three-way analysis of variance was therefore conducted for each scale. For the GATMR, the ANOVA showed a significant main effect for all three variables: marital status, social class, and ethnicity. F-values were $7.78,19.29$, and 12.53 , respectively, with $p<.01, .001$, and .001 with single mothers showing less traditional scores. There were no significant interactions. For the GATCR, 
Gender-Attitudes Toward Child Rearing, there were significant main effects for class and ethnicity but none for marital status. (F-values for marital status, class, and ethnicity were $.88,32.84$, and $22.63 ; p<.001$ for class and ethnicity).

Ethnicity. Table III shows a relationship between ethnicity and scores on both attitude scales; for both scales African Americans indicated more gender-based traditionalism. As with marital status, however, it is important to see whether or not this relationship is affected by social class. In addition, previous research suggests that gender might moderate the relationship, showing an interaction with the other variables. Accordingly, a three-way analysis of variance was conducted for each scale. In each case, the ANOVA showed a significant main effect for all there variables: ethnicity, gender, and class. For the GATMR, F-values were 14.21, 15.29, and 20.32 for ethnicity, gender, and class, respectively, with each $F$ significant at $<.001$. For the GATCR, the F-values were 19.85 for ethnicity, 7.01 for gender, and 31.09 for class, with $p<.001$ for each. There were no significant interactions.

In all comparisons between groups in the same class and gender category, the mean for African Americans was in the more gender-traditional direction. For the GATMR, the lowest mean score (most gender-based), 14.91, was obtained by the African American men in the lower class, the second lowest by the African American women in the lower class. For the GATCR, the lowest mean score, 21.49, was obtained by the African American women in the lower class, the second lowest by the African American men, and the third lowest by the African American middle-class men. For both scales, the highest scores (least traditional) were obtained by the middle-class, European American women $(19.46,24.71)$ and the second highest scores were obtained by the middle-class, African American women (18.44, 23.68). Thus for both scales, although there are also class and gender differences across ethnic groups, African American status is related to more gender-role traditional attitudes.

\section{Division of Tasks}

Perhaps the most direct construct validity test conducted here is the relationship between the GATMR, the Gender-based Attitudes Toward Marital Roles, and the actual division of roles as reported by the family members. In Table IV, correlations are reported between the parents' responses on the GATMR and the reports by the mother, father, and thirdor fourth-grade child of the extent to which the mother is the exclusive or major parent in carrying out the various tasks that have been traditionally 
Table IV. Correlations Between GATMR and the Extent to Which the Mother Has the Major Role in Traditionally Feminine Household Tasks

\begin{tabular}{lccc}
\hline & \multicolumn{3}{c}{ Mother's greater participation in "Women's" tasks } \\
\cline { 2 - 4 } & $\begin{array}{c}\text { Reported by } \\
\text { child }\end{array}$ & $\begin{array}{c}\text { Reported by } \\
\text { mother }\end{array}$ & $\begin{array}{c}\text { Reported by } \\
\text { father }\end{array}$ \\
\hline $\begin{array}{c}\text { GATMR score } \\
\text { Mother's }\end{array}$ & $-.2015^{a}$ & $-.3138^{a}$ & $-.2973^{a}$ \\
Father's & $-.2125^{a}$ & $-.3150^{a}$ & $-.3963^{a}$ \\
\hline
\end{tabular}

${ }_{p} p<.01$, two tailed.

considered feminine tasks. The correlations for both the mothers' and the fathers' scores on the GATMR indicate that when the parents endorse a more gender-based attitude toward family roles, the mother is more likely to be the major or exclusive performer of the tasks that have been traditionally considered "women's tasks." A traditional attitude on the GATMR is significantly related to the family's reports of the actual division of roles at $p<.01$ whether the reporter is the mother, father or child.

\section{Children's Stereotypes}

In Table $\mathrm{V}$, the correlations are reported between the parents' responses on each scale, the GATMR and the GATCR, and each component of the children's gender-stereotype scale. When parents gave nonstereotyped responses on the GATMR and on the GATCR, their children also gave nonstereotyped responses indicating that men were capable of carrying out activities traditionally assigned to women, and women were capable of carrying out activities traditionally assigned to men. All the relationships were statistically significant in the predicted direction.

\section{Independence of Daughters}

It was predicted that daughters of parents who indicated less stereotyped attitudes would be rated by their teachers as higher on Assertive Social Skills and would show a more internal Locus of Control. As Table VI shows, daughters whose mothers indicated less stereotyped attitudes on each scale showed significantly more internal locus of control scores whereas there was no relationship for boys. For the teacher ratings of Assertive Social Skills, there were no significant relationships to the mothers' scores on the Gender Attitudes toward Marital Roles for either boys or 
Table V. Correlations Between GATMR and GATCR and Children's Stereotypes ${ }^{a}$

\begin{tabular}{lccc}
\hline & \multicolumn{3}{c}{ Children's stereotypes } \\
\cline { 2 - 4 } Parents' stereotypes & $\begin{array}{c}\text { About traditional } \\
\text { male activities }\end{array}$ & $\begin{array}{c}\text { About traditional } \\
\text { female activities }\end{array}$ & $N$ \\
\hline GATMR & $.2039^{c}$ & & \\
$\quad$ Mother's response & $.1854^{c}$ & $.1642^{c}$ & 364 \\
Father's response & & $.1944^{c}$ & 213 \\
GATCR & $.2519^{c}$ & & \\
Mother's response & $.1614^{b}$ & $.2225^{c}$ & 364 \\
Father's response & $.1429^{b}$ & 213 \\
\hline
\end{tabular}

${ }^{a}$ High score on all scales indicates a less gender-stereotyped attitude.

${ }^{b} p<.05$, two tailed.

$c_{p}<.01$, two tailed.

girls. However, mothers' Gender Attitudes toward Child Rearing was not significantly related for boys but showed a trend level for girls: less stereotyped attitudes were related to higher teacher ratings of assertive skills, significant at $p<.10$.

Statistical comparisons were made for the difference between the coefficients obtained for boys and girls in the three cases where the coefficients attained a significance level of at least $p<.10$, using the Z-score transformation formula as recommended by Cohen and Cohen (1983). For all three coefficients, the girls' were significantly higher than the boys'. For Locus of Control, the Z-score for the GATMR was $-4.08, p<.01$; for the GATCR, $\mathrm{Z}=-3.09, p<.01$. For Assertive Skills, $\mathrm{Z}=4.38, p<.01$.

Table VI. Correlations Between Mothers' GATMR and GATCR Scores and Child's Positive Assertiveness and Locus of Control

\begin{tabular}{llll}
\hline & GATMR & GATCR & $N$ \\
\hline Assertive Social skills & & & \\
$\quad$ Girls & .1033 & $.1283^{a}$ & 186 \\
Boys & .0404 & -.0870 & 178 \\
& & & \\
Locus of control & $-.1868^{a}$ & $-.1581^{b}$ & 186 \\
$\quad$ Girls & -.0727 & -.0955 & 178 \\
$\quad$ Boys & & & \\
\hline${ }^{a} p<.10$, two tailed. & & &
\end{tabular}


Table VII. Correlations Between Mothers' GATCR Scores and Achievement Test Scores by Gender and Social Class

\begin{tabular}{lccccc}
\hline & \multicolumn{2}{c}{ Middle class } & & \multicolumn{2}{c}{ Lower class } \\
\cline { 2 - 3 } \cline { 5 - 6 } & Boys & Girls & & Boys & Girls \\
\hline Reading & .0126 & .1396 & & $.2379^{a}$ & $.2320^{a}$ \\
Language & .0275 & $.2340^{a}$ & & .1239 & .1017 \\
Math & -.1286 & $.2890^{b}$ & & $.2032^{a}$ & $.2303^{a}$ \\
\multicolumn{1}{c}{$N=$} & 112 & 93 & & 66 & 93 \\
\hline$a_{p}<.05$, two tailed. & & & & \\
$b_{p}<.01$, two tailed.
\end{tabular}

\section{Achievement Tests}

The correlations between mothers' scores on the GATCR and the children's scores on the three achievement tests are presented in Table VII, separately by social status. It was our hypothesis that the daughters whose mothers had less stereotyped scores on the GATCR would show higher achievement scores with no relationship for boys. This hypothesis receives support in the middle class for language and math, but was not supported in the lower class. In the middle class, correlations are significant for girls for language and math and showed no relationship for boys on language and a nonsignificant negative direction on math. In both cases, the coefficients are significantly different for boys and girls. Using the Z-score transformation formula (Cohen \& Cohen, 1983), the Z-score for language is 20.16 and for math is 47.55 , both significant at $p<.001$.

The correlation for middle-class girls was not significant on reading, although it was higher than the correlation for boys. The hypothesis was not confirmed for the lower status group as significant correlations were shown for both boys and girls on reading and math, and for neither on language.

\section{SUMMARY AND CONCLUSIONS}

The main purpose of this paper is to present two new measures of gender-stereotyped attitudes toward family roles, one dealing with husbandwife roles and one dealing with differences in views about rearing sons and daughters. Both measures are short, easily-scored, can be self-administered, and are intended primarily for research relevant to children's socialization. 
They tap an important link in the process by which the family environment affects how children develop. The measure of husband-wife roles (GATMR) includes items dealing with the division of labor and power. The measure of child-rearing attitudes (GATCR) includes items dealing with values that are relevant to adult goals, particularly independence and achievement, two qualities identified as being important in explaining gender differences in motivation and behavior. Separate factor analyses were conducted for married mothers, single mothers, and married fathers. Reliabilities for the two scales varied from .77 to .85 , the lowest for fathers on the child-rearing scale.

As part of an examination of the construct validity of the two measures, their relationships to various demographic variables were examined to see if these were consistent with previous research. As in previous work on gender-role attitudes, higher socioeconomic status, more education, being female, and maternal employment predicted to less gender-stereotyped scores on both measures.

Previous research on gender attitudes comparing African Americans and European Americans has suggested that African Americans may be more accepting of women's occupational involvement but more traditional with respect to family roles. In this analysis, African Americans endorsed more gender-stereotyped views on both scales. This may reflect the content of the items, since none deal with whether or not a woman should be employed, but may also reflect a greater acceptance of women's employment in the United States among European Americans today than when the previous research was conducted (Thornton, Alwin, and Camburn, 1983).

Few previous studies have examined the relationship between the mother's marital status and gender attitudes. In this analysis, single-mother status was associated with less gender-role stereotyping on the GATMR, with class and ethnicity controlled. The mother's marital status was not related to GATCR scores.

Thus, the relationship to demographic variables were consistent with previous results for gender attitudes where such results were well established. For ethnicity and marital status, they supplemented previous findings.

More direct validation of the measures was established, however, by showing that the responses of the married mothers and fathers on the GATMR, the measure of marital role attitudes, were significantly correlated to separate reports by each parent and the child of the extent to which fathers actually participated in household activities that have been stereotypically cast as part of the woman's role. Both scales were also significantly related to children's gender stereotyping. Children who gave more 
responses indicating that only men could do activities traditionally designated as male activities and only women could do activities traditionally designated as female activities had parents who obtained more stereotyped scores on the GATMR and the GATCR.

Finally, hypotheses were tested to see if mothers who held less gender-stereotyped views about child rearing had daughters who had a more internal locus of control, showed more independent coping skills, and obtained higher achievement scores. The hypothesis was fully supported for locus of control and received partial support for independent coping skills and the achievement scores. Less stereotyped attitudes toward marital roles related to daughters' more internalized locus of control, as predicted, but not to the measure of coping skills. These results support the validity and value of the measures and also add substantively to the research on the socialization of gender differences.

\section{REFERENCES}

Barber, B. L. (1990). The impact of family structure on the development of adolescents' family and work related values, beliefs, and aspirations. Doctoral dissertation, University of Michigan, Ann Arbor, MI.

Barber, B. L., \& Eccles, J. S. (1992). Long-term influence of divorce and single parenting on adolescent family and work-related values, behaviors, and aspirations. Psychological Bulletin, 111, 108-126.

Baruch, G. K., \& Barnett, R. C. (1981). Fathers' participation in the care of their preschool children. Sex Roles, 7, 1043-1056.

Beere, C. A. (1990). Gender roles: A handbook of tests and measures. New York: Greenwood Press.

Beere, C. A., King, D. W., Beere, D. B., \& King, L. A. (1984). The Sex-Role Egalitarianism Scale: A measure of attitudes toward equality between the sexes. Sex Roles, 10, 563-576.

Belk, S. S., \& Snell, W. E. (1986). Beliefs about women: Components and correlates. Personality and Social Psychology Bulletin, 12, 403-413.

Bem, S. L. (1974). The measurement of psychological androgyny. Joumal of Consulting and Clinical Psychology, 42, 155-162.

Binion, V. J. (1990). Psychological androgyny: A Black female perspective. Sex Roles, 22, 487-507.

Block, J. H. (1973). Conceptions of sex role: Some cross cultural and longitudinal perspectives American psychologist, 28, 512-526.

Block, J. H. (1983). Differential premises arising from differential socialization of the sexes: Some conjectures. Child Development, 54, 1335-1354.

Brooks-Gunn, J. (1985). Maternal beliefs about children's sex-typed characteristics as they relate to maternal behavior. In I. E. Sigel (Ed.), Parental belief systems: The psychological consequences for children. Hillside, NJ: LEA Publishers.

Brown, P., \& Manela, R. (1978). Changing family roles: Women and divorce. Journal of Divorce, 1, 315-328.

Burge, P. (1981). Parental child-rearing sex role attitudes. Home Economics Research Journal, 9, 193-199.

Cohen, J., \& Cohen, P. (1983). Applied mutual regression/correlation analysis for the behavioral sciences. Hillsdale, NJ: Lawrence Erlbaum Associates. 
Deaux, K., \& Lewis, L. L. (1984). Structure of gender stereotypes: Interrelationships among components and gender label. Journal of Personality and Social Psychology, 46, 991-1004.

Dunn, M. S. (1960). Marriage and expectations of adolescents. Marriage and Family Living, $22,99-111$.

Eccles, J. S. (1985). Sex differences in achievement patterns. In T. Sondereggen (Ed.), Nebraska symposium on motivation. Lincoln: University of Nebraska Press.

Eccles, J. S,. \& Hoffman, L. W. (1984). Sex roles, socialization, and occupational behavior. In H. Stevenson \& A. Siegal (Eds.), Child development research and social policy. Chicago, IL: Chicago University Press.

Entwisle, D., \& Greenberger, E. (1972). Adolescents' views of women's work role. American Journal of Orthopsychiatry, 42, 648-656.

Fagot, B. I. (1974). Sex differences in toddlers' behavior and parental reaction. Developmental Psychology, 10, 554-558.

Fagot, B. I. (1978). The influence of sex of child on parental reactions to toddler children. Child Development, 49, 459-465.

Fagot, B. I. (1982). Adults as socializing agents. In T. M. Field, A. Huston, H. C. Quay, L. Troll, \& G. E. Finely (Eds.), Review of human development. New York: Wiley.

Greenberger, E., Goldberg, W. A., Crawford, T. J., \& Ganger, J. (1988). Beliefs about the consequences of maternal employment for children. Psychology of Women Quarterly, 12, 35-59.

Herbst, P. G. (1952). The measurement of family relationships. Human Relations, 5, 3-30.

Herzog, A. R., Bachman, J. G., \& Johnston, L. D. (1983). Paid work, child care, and housework: A national survey of high school seniors' preferences for sharing responsibilities between husband and wife. Sex Roles, 9, 109-135.

Hetherington, E. M., \& Camara, K. A. (1984). Families in transition. In R. D. Parke (Ed.), Review of child development research, (Vol. 7, 398-439). Chicago: University of Chicago Press.

Hightower, A. D., Work, W. C., Cowen, E. L., Lotyczewski, B. S., Spinell, A. P., Guare, J. C., \& Rohrbeck, C. A. (1986). The Teacher-child rating scale: A brief objective measure of elementary children's social problem behaviors and competencies. School Psychology Review, 15, 393-409.

Hoffman, L. W. (1960). Effects of the employment of mothers on parental power relations and the division of household tasks. Marriage and Family Living, 22, 127-135.

Hoffman, L. W. (1972). Early childhood experiences and women's achievement motives. Journal of Social Issues, 28, 129-156.

Hoffman, L. W. (1977). Changes in family roles, socialization, and sex differences. American Psychologist, 32, 644-657.

Hoffman, L. W. (1989). Effects of maternal employment in the two-parent family. American Psychologist, 44, 283-292.

Hoffman, L. W., Paris, S., \& Hall, E. (1993). Developmental psychology today (6th ed.). New York: McGraw-Hill.

Hollingshead, A. B. (1970). Four-factor index of social status. Unpublished manuscript, Department of Sociology, Yale University, New Haven, CT.

Huston, A. C. (1983). Sex-typing. In P. H. Mussen (Ed.), Handbook of child psychology (4th ed., Vol. 4). New York: Wiley.

Huston, A. C. (1985). The development of sex typing: Themes from recent research. Developmental Review, 5, 1-17.

Jacobson, A. H. (1951). Conflicts in attitudes toward the marital roles of husband and wife. Washington State University Research Studies, 19, 103-106.

Katz, P. A., \& Walsh, P. V. (1991). Modification of children's gender-stereotyped behavior. Child Development, 62, 338-351.

Kohlberg, L. (1966). A cognitive-development analysis of children's sex-role concepts and attitudes. In E. E. Maccoby (Ed.), The development of sex differences. Stanford: Stanford University Press.

Lytton, H., \& Romney, D. M. (1991). Parents differential socialization of boys and girls: A meta-analysis. Psychological Bulletin, 109, 2, 267-296. 
Martin, C. L. (1987). A ratio measure of sex stereotyping. Journal of Personality and Social Psychology, 52, 489-499.

McLoyd, V. C. (1993). Employment among African American mothers in dual earner families: Antecedents and consequences for family life and child development. In J. Frankel (Ed.), Employed mothers and the family context. New York: Springer.

Miller, S. M. (1975). Effects of maternal employment on sex role perception, interests, and self-esteem in kindergarten girls. Developmental Psychology, 11, 405-406.

Nowicki, S. Jr., \& Strickland, B. R. (1973). A locus of control scale for children. Journal of Consulting and Clinical Psychology, 40, 148-154.

Osmond, M. W., \& Martin, P. Y. (1975). Sex and sexism: A comparison of male and female sex-role attitudes. Journal of Marriage and Family, 37, 744-758.

Scanzoni, J. H. (1975). Sex roles, life styles, and child bearing. New York: Free Press.

Schaninger, C. M., \& Buss, W. C. (1986). The relationship of sex-role norms to couple and parental demographics. Sex Roles, 15, 77-94.

Signorella, M. L., \& Liben, L. S. (1985). Assessing children's gender-stereotyped attitudes. Psychological Documents, 15, 7.

Smith, T. W. (1985). Working wives and women's rights: The connection between the employment status of wives and the feminist attitudes of husband's. Sex Roles, 12, 501-508.

Spence, J. T., Helmreich, R. L., Stapp, J. (1973). A short version of the Attitudes toward Women Scale (IS). Bulletin of the Psychonomic Society, 2, 219-220.

Spence, J. T., Helmreich, R. L., \& Stapp, J. (1974). The personal attributes questionnaire: A measure of sex role stereotypes and masculinity-femininity. Journal Supplement Abstract Service Catalog of Selected Documents in Psychology, 4, 43-44.

Thornton, A., Alwin, D. F., \& Camburn, D. (1983). Causes and consequences of sex-role attitudes and attitude change. American Sociological Review, 48, 211-227.

U. S. Bureau of the Census (1993). Statistical abstract of the United Sates (113th ed.). Washington, DC: U.S. Government Printing Office.

Vogel, S., Browerman, I., Browerman, D., Clarkson, F., \& Rosenkrantz, P. (1970). Maternal ernployment and perception of sex roles among college students. Development Psychology, 3, 304-391.

Zaslow, M. J. (1987). Sex differences in children's response to maternal employment. Unpublished manuscript prepared for the Committee on Child Development Research and Public Policy, National Research Council, Washington, DC. 